\title{
Cardiovascular malformations in Turner's and Noonan's syndrome
}

\author{
L. G. VAN DER HAUWAERT, J. P. FRYNS, M. DUMOULIN, AND N. LOGghe \\ From the Department of Paediatrics, Section of Paediatric Cardiology and the Division of Human Genetics \\ University Hospital Gasthuisberg, 3000 Leuven, Belgium
}

SUMMARY The cardiovascular findings in 9 patients with Turner's syndrome and 9 patients with Noonan's syndrome are described. Of the 9 patients with Turner's syndrome, 4 had coarctation of the aorta, 4 aortic stenosis, and the remaining patient both these lesions. All patients with Noonan's syndrome had pulmonary valve stenosis. In addition, 2 children had an atrial septal defect and 1 an atrial septal defect associated with mild supravalvar pulmonary stenosis and anomalous drainage of the right upper pulmonary veins. In the majority of patients the electrocardiogram was different from the pattern usually seen in pulmonary valve stenosis: the QRS axis in the frontal plane was superiorly oriented in 7 out of 9 cases and in 2 patients evidence of right ventricular hypertrophy was lacking in the right praecordial leads; in 5 patients an $\mathrm{rS}$ complex was seen in the left praecordial leads. Gross thickening of pulmonary valve cusps was found at operation in 4 of the 8 patients who were operated on.

Although phenotypically related, Turner's and Noonan's syndromes are associated with different and distinct cardiovascular anomalies.

The Turner phenotype is often associated with cardiovascular malformations. Survey studies indicate that coarctation is the most common finding in Turner's syndrome with classical 45 X0 karyotype or a structurally abnormal second X chromosome (Lemli and Smith, 1963; Rainier-Pope et al., 1964) whereas a wide variety of anomalies is found in individuals with the Turner phenotype and normal karyotype (Vernant et al., 1966). In recent years this latter combination has usually been called Noonan's syndrome. The predominance of pulmonary stenosis in this syndrome has been clearly shown (Celermajer et al., 1968; Noonan, 1968; Nora et al., 1970; Siggers and Polani, 1972; Nora et al., 1974). However, relatively few patients have been reported with complete chromosomal, phenotypic, and cardiological evaluation. We, therefore, reviewed our patient material with particular attention to the cardiovascular findings in Noonan's syndrome.

\section{History and definitions}

Turner's syndrome, according to the original description (1938), is characterised by short stature, sexual and skeletal infantilism, webbing of the neck

Received for publication 12 April 1977 (pterygium colli), and cubitus valgus. Turner, obviously, was unaware of Ullrich's earlier report (1930) on a similar syndrome. Among other findings, Ullrich described small stature, webbing of the neck, cubitus valgus, and lymphoedema of the extremities. He did not include sexual infantilism in the list of stigmata, probably because his patients had not reached puberty. In later years, follow-up of sexual development and endocrine and laparoscopic studies showed that primary ovarian dysgenesis and lack of secondary sexual characteristics were an essential part of Turner's syndrome.

In 1959 the first chromosome study showed the absence of one $\mathrm{X}$ chromosome in female patients with Turner's syndrome (Ford et al., 1959). This discovery was in keeping with the earlier findings of Polani et al. (1956) that sex chromatin, determined from the buccal smear, was negative in many of these patients. In addition to the absence of one $X$ chromosome, which is the usual finding, various structural anomalies of the second $\mathrm{X}$ chromosome have been described (Van den Berghe, 1966).

In the following years an increasing number of female patients, as well as males, with Turner phenotype but with a normal karyotype, were described and terms such as 'male Turner's syndrome', and 'Turner's syndrome with $46 \mathrm{XX}$ karyotype' have been used in published reports. In 
1963 Noonan and Ehmke described a 'new syndrome' and reported on 9 patients, 6 male and 3 female, with remarkably similar facies and with a previously unrecognised combination of valvar pulmonary stenosis and multiple extracardiac anomalies. In this and a later publication (Noonan, 1968) the following stigmata were mentioned: hypertelorism, a relatively short neck (true webbing being exceptional), low-set ears, ptosis, exophthalmos, chest deformities, and scoliosis. Most patients were below the tenth centile for height. Mental retardation was common. In some patients agonadism was noted but in others gonadal function and fertility were normal. In all the karyotype was normal.

According to Noonan (1968) the patients described by her represent a syndrome distinct from Turner's. She also expressed the view that most of the previously reported female patients with normal karyotype and a number of patients with 'male Turner's syndrome' and hypertelorism fit the newly described syndrome. Familial occurrence, already indicated by Noonan's observations, was confirmed by Nora and Sinha (1967) who suggested an autosomal dominant trait as mode of inheritance.

Some authors (Siggers and Polani, 1972) do not consider Noonan's syndrome to be a distinct entity and use the term 'Turner's syndrome' also to describe male patients with normal XY karyotype and hypogonadism. These authors use the term Ullrich's syndrome for male and female patients with features of Turner's syndrome but normal chromosomes and normal sexual development. Others (Ehlers et al., 1972) distinguish 'Turner's syndrome' from 'Turner's phenotype' and subdivide the latter according to the karyotype (46, XX or $46, \mathrm{XY}$ ). As a result, the terminology of Turner's syndrome and phenotypically related conditions has become very confusing. There is a trend however, particularly in cardiological publications, to use the term Noonan's syndrome for all patients, male or female, with a Turner phenotype and a normal karyotype (Char et al., 1972; Phornphutkul et al., 1973; Hirsch et al., 1975). On the assumption that the patients originally described by Ullrich probably represent a heterogeneous group, consisting partly of true Turner patients and partly of individuals with Turner's phenotype and normal karyotype, Nora et al. (1972, 1975) proposed the term Ullrich-Noonan syndrome for the latter group.

\section{Patients and methods}

The patient material includes 18 patients, 9 presenting with classical Turner's syndrome and 9 with Noonan's syndrome ( 5 boys and 4 girls). Their ages ranged from 5 to 17 years. All patients were primarily referred for cardiological examination. A detailed family history was obtained, and in all cases with Noonan's syndrome a systematic examination of the parents and occasionally other relatives was carried out. Cytogenetic examination was performed at the Division of Human Genetics. In order to be accepted, the diagnosis of Noonan's syndrome had to be made independently by a paediatric cardiologist and a geneticist. As suggested in the introduction, the 9 patients with features of Turner's syndrome and absence or anomaly of the second $\mathrm{X}$ chromosome will be referred to as having Turner's syndrome, whereas female (4 cases) and male patients (5 cases) with features suggesting Turner's syndrome and normal karyotype, will be referred to as having Noonan's syndrome. The cardiological evaluation included electrocardiograms, phonocardiograms, carotid and jugular pulse tracings, and chest $x$-rays. Cardiac catheterisation was carried out in 14 patients. In those with severe pulmonary stenosis, right ventriculograms were made.

\section{Results}

\section{(1) TURNER'S SYNDROME}

In all 9 patients sex chromatin distribution in buccal smear was negative. Eight had an X0 karyotype, the remaining child a mosaic pattern 45, X0/46, XX.

On clinical examination all 9 patients showed the typical Turner's stigmata. Their height was below the third centile. Oedema of hands and feet was seen or mentioned as a striking feature in 4 children, particularly during the first year of life. In 2 patients this led to the erroneous diagnosis of congestive heart failure. The oldest girl, 17 years of age, had primary amenorrhoea.

The cardiac findings are shown in Table 1. Four patients, 3 of whom had operations, had coarctation of the aorta. In 2 the angiocardiographic and surgical findings were typical of adult type coarctation. In one girl the blood pressure in the right arm $(120 / 95 \mathrm{mmHg})$ was lower than in the left arm $(155 / 105 \mathrm{mmHg})$ and the aortogram showed an anomalous right subclavian artery originating immediately below the coarctation and passing behind the oesophagus. In this child resection of the coarctation was thought to be technically difficult, and surgical correction was achieved by inserting a patch in the narrowed segment. Postoperative blood pressures in the upper and lower limbs were equal. One patient died in irreversible shock, one week after operation, as a result of extensive necrotising arteritis involving the superior mesenteric artery. Histological examination showed 
Table 1 Cardiovascular anomalies and karyotype in 18 patients with Turner's or Noonan's syndrome

\begin{tabular}{lllll}
\hline $\begin{array}{l}\text { Cardiovascular } \\
\text { anomalies }\end{array}$ & \multicolumn{3}{l}{ Karyotype } \\
\cline { 2 - 4 } & $45, X 0$ & $45, X 0 / 46, X X$ & $46, X X$ & $46, X Y$ \\
\hline $\begin{array}{l}\text { Coarctation of } \\
\text { aorta }\end{array}$ & 4 & 1 & \\
$\begin{array}{c}\text { Aortic stenosis } \\
\text { Coarctation with } \\
\text { aortic stenosis }\end{array}$ & 3 & 1 & 3 & 3 \\
$\begin{array}{c}\text { Pulmonary stenosis } \\
\text { Pulmonary stenosis } \\
\text { with atrial septal } \\
\text { defect }\end{array}$ & & 1 & 2 \\
\hline
\end{tabular}

acute arteritis and inflammatory lesions in the vessel wall. No changes characteristic of cystic medial necrosis were found in the aorta.

Four patients had aortic stenosis. The association of a diamond-shaped murmur at the 2 nd right intercostal space and a loud ejection sound at the lower left sternal border indicated valvar stenosis. The external carotid tracings showed coarse vibrations on the ascending limb and summit but no significant prolongation of left ventricular ejection time. The electrocardiogram was normal. As the left ventricular-aortic peak systolic gradient did not exceed $40 \mathrm{mmHg}$, these patients were not referred for operation.
One patient had combined coarctation and valvar aortic stenosis. The electrocardiogram showed left ventricular hypertrophy. Right heart catheterisation showed no abnormality. At left heart catheterisation the following pressures were measured: left ventricle $175 / 10 \mathrm{mmHg}$, ascending aorta $125 / 75$ $\mathrm{mmHg}$, descending aorta beyond the coarctation $85 / 60 \mathrm{mmHg}$. At operation a classical coarctation was found and resected. One commissure of the stenosed and bicuspid aortic valve was opened. The postoperative course was uneventful.

\section{(2) NOONAN'S SYNDROME}

This series includes 4 girls and 5 boys. Extensive cytogenetic examination, including the different banding techniques (G-, Q-, C- and T-banding), was normal in all patients. The clinical findings and the main stigmata are summarised in Table 2. Height was below the third centile in only 3 children. All patients had a characteristic facial appearance. The most constant features were hypertelorism, unilateral or bilateral ptosis, and a short neck with low-set ears (Fig. 1 and 2). Frank webbing of the neck was present in 3 of the 4 girls and in 1 of the 5 boys. Intellectual development was normal in 6 and moderately impaired in 3 patients. Genital development was normal in 2 and retarded in 3 others of the 5 boys, one of whom had bilateral

Table 2 Extracardiac manifestations in 9 patients with Noonan's syndrome

\begin{tabular}{|c|c|c|c|c|c|c|c|c|c|}
\hline \multirow[t]{2}{*}{ Clinical findings } & \multicolumn{9}{|c|}{ Case No. } \\
\hline & 10 & 11 & 12 & 13 & 14 & 15 & 16 & 17 & 18 \\
\hline $\begin{array}{l}\text { Sex, age (y) } \\
\text { Height (centile) }\end{array}$ & $\begin{array}{l}\text { F13 } \\
\text { P10 }\end{array}$ & $\begin{array}{l}\text { F15 } \\
\text { P25 }\end{array}$ & $\begin{array}{l}\text { F13 } \\
\text { P3 }\end{array}$ & $\begin{array}{l}\text { F12 } \\
\text { P10 }\end{array}$ & $\begin{array}{l}\text { M17 } \\
\text { P3 }\end{array}$ & $\begin{array}{l}\text { M4 } \\
\text { P3 }\end{array}$ & $\begin{array}{l}\text { M6 } \\
\text { P3 }\end{array}$ & $\begin{array}{l}\text { M10 } \\
\text { P10 }\end{array}$ & $\begin{array}{l}\text { M15 } \\
\text { P25 }\end{array}$ \\
\hline \multicolumn{10}{|l|}{ Craniofacial stigmata } \\
\hline Eyes: ptosis & + & & + & & & + & + & + & + \\
\hline hypertelorism & + & + & + & + & + & + & + & + & \\
\hline epicanthic folds & + & + & + & & & + & + & + & \\
\hline Narrow maxilla & & & & + & & & & + & + \\
\hline High-arched palate & & + & + & & + & & + & & + \\
\hline Micrognathia & + & + & + & + & & & & & \\
\hline Short neck & + & + & + & + & + & + & + & + & + \\
\hline Webbed neck & + & + & + & & + & & & & \\
\hline Low posterior hairline & + & + & + & & + & + & + & + & \\
\hline Low-set ears & + & & + & + & + & + & + & & \\
\hline \multicolumn{10}{|l|}{ Thorax } \\
\hline Pectus excavatum & & + & + & + & & & + & + & + \\
\hline Widely spaced nipples & & + & + & + & & & + & & \\
\hline \multicolumn{10}{|l|}{ Extremities } \\
\hline Small hands and feet & & + & + & + & & & + & + & \\
\hline Cubitus valgus & & & & + & & & & + & + \\
\hline Lymphoedema of hands and feet & & & & & + & & + & & \\
\hline Clinodactyly (5th finger) & & & + & & + & + & & & \\
\hline Brachymetacarpia (4-5) & & & & + & & & & & + \\
\hline Pigmented naevi & & + & + & & & & & + & + \\
\hline Sexual development & & & & & & & & + & + \\
\hline $\begin{array}{l}\text { Normal } \\
\text { Retarded }\end{array}$ & + & + & + & + & + & + & + & $\top$ & $T$ \\
\hline Mental retardation & & & & + & + & + & & & \\
\hline Family history & & & & & & & & & \\
\hline stigmata in one parent and/or sibs & & + & & & & & & & + \\
\hline Age of parents at birth & & & 26 & 33 & 35 & & & 25 & 28 \\
\hline $\begin{array}{l}\text { Mother (y) } \\
\text { Father }(y)\end{array}$ & & 41 & 27 & 40 & 36 & & 34 & 27 & 30 \\
\hline
\end{tabular}




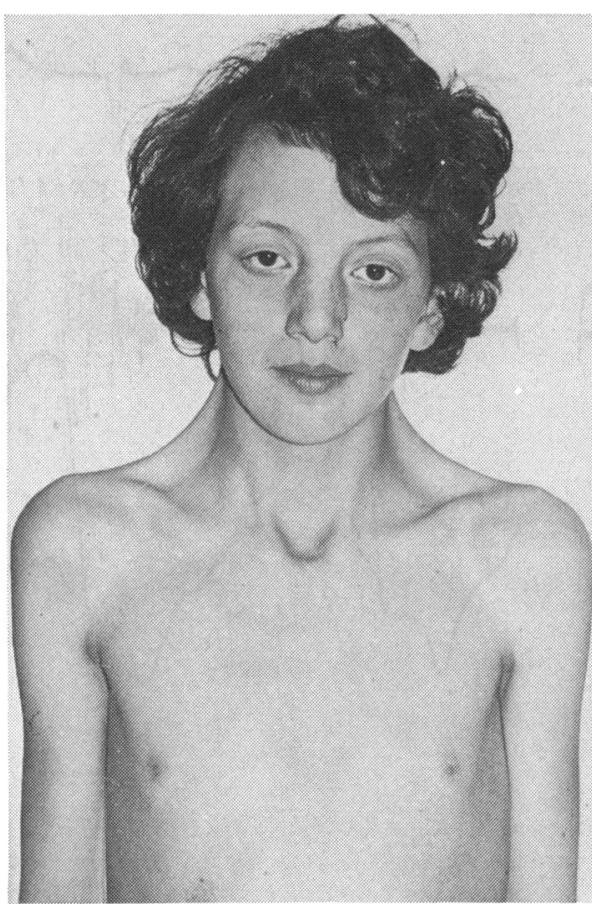

Fig. 1 Case 10 at age 13 years. Note hypertelorism, epicanthic folds, ptosis, webbing of the neck, and widely spaced nipples.

cryptorchidy. Three girls reached puberty and menarche at the expected age. One of them is married and has a son who has typical Noonan stigmata but no heart defect. The family history was positive in one other case, whose father had a few stigmata and paternal grandmother more distinct features including short stature, ptosis, and a short neck.

Pulmonary stenosis was the major cardiac anomaly in all patients (Table 1). The auscultatory and phonocardiographic findings are summarised in Table 3. An ejection sound was heard and

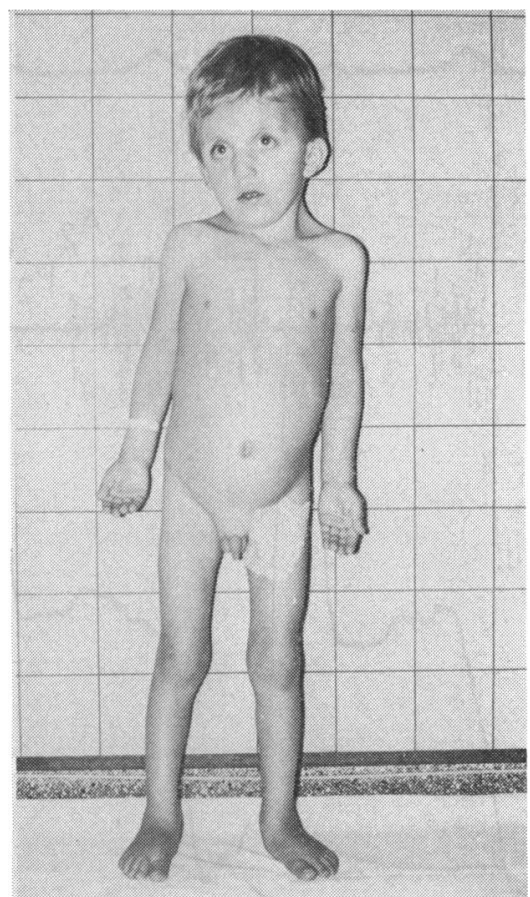

Fig. 2 Case 16 at age 6 years, showing short stature, typical facial features, and webbing of the neck. Testes were undescended.

Table 3 Auscultatory, phonocardiographic, and electrocardiographic findings in 9 patients with Noonan's syndrome

\begin{tabular}{|c|c|c|c|c|c|c|}
\hline Case No. & $\begin{array}{l}\text { Intensity systolic } \\
\text { murmur } \\
(2 L I S)\end{array}$ & $\begin{array}{l}\text { Pulmonary } \\
\text { ejection sound }\end{array}$ & $\begin{array}{l}\text { A2-P2 interval } \\
\text { (ms) }\end{array}$ & Mean QRS axis & $\begin{array}{l}\text { QRS pattern } \\
V 3 R \text { and } V 1\end{array}$ & $\begin{array}{l}\text { QRS pattern } \\
\text { in V5 and V6 }\end{array}$ \\
\hline $\begin{array}{l}10 \\
11 \\
12 \\
13 \\
14 \\
15 \\
16 \\
17 \\
18\end{array}$ & $\begin{array}{l}5 / 6 \\
6 / 6 \\
4 / 6 \\
3 / 6 \\
4 / 6 \\
4 / 6 \\
4 / 6 \\
3 / 6 \\
3-4 / 6\end{array}$ & $\begin{array}{l}+ \\
+ \\
+ \\
+ \\
+ \\
+ \\
0 \\
0 \\
+\end{array}$ & $\begin{array}{l}100-120 \\
90-100 \\
50-70 \\
40-70 \\
40-60 \\
70-80 \\
\text { P2 not recorded } \\
60-70 \\
60-70\end{array}$ & $\begin{array}{l} \pm 180^{\circ} \\
-120^{\circ} \\
-120^{\circ} \\
-100^{\circ} \\
+115^{\circ} \\
-135^{\circ} \\
-140^{\circ} \\
-130^{\circ} \\
-70^{\circ}\end{array}$ & $\begin{array}{l}\text { rs } \\
\text { Rs } \\
\text { rsr' } \\
\mathbf{R} \\
\text { rsR' } \\
\text { rsR' } \\
\text { Rs } \\
\text { Rs } \\
\text { rsR' }\end{array}$ & $\begin{array}{l}\text { rS } \\
\text { rS } \\
\text { rS } \\
\text { qRS } \\
\text { qRs } \\
\text { qRS } \\
\text { rS } \\
\text { rS } \\
\text { qRs }\end{array}$ \\
\hline
\end{tabular}

recorded on the phonocardiogram in 7 patients, but in the 2 remaining patients, both of whom had severe stenosis and valvar dysplasia, an ejection sound could neither be heard nor recorded. In 8 patients wide splitting of the second sound, usually with some inspiratory increase, was recorded (Fig. 3). The width of the splitting was in accordance with the severity of the stenosis. In 1 patient with pulmonary valve dysplasia the pulmonary closure sound could not be identified on the phonocardiogram.

The electrocardiogram often showed an unusual 

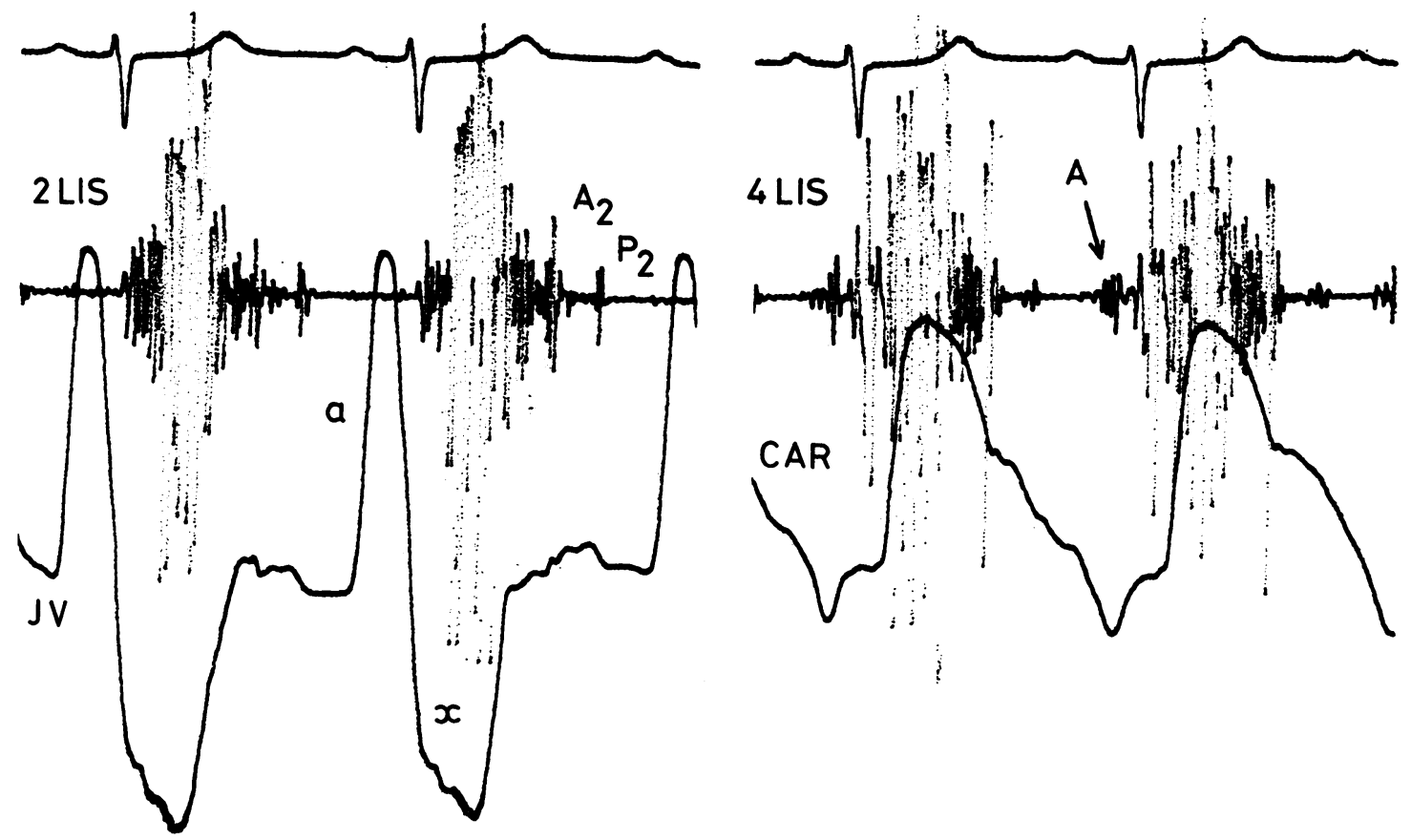

Fig. 3 Phonocardiogram of case 10, a 13-year-old girl with Noonan's syndrome and severe pulmonary valve stenosis. At the second left intercostal space (2 LIS) a loud midsystolic murmur and a widely split second sound were seen: the interval between its aortic $\left(A_{2}\right)$ and pulmonary component $\left(P_{2}\right)$ is $120 \mathrm{~ms}$. The external jugular venous tracing $(\mathcal{F V})$ shows a giant a wave and deep $x$ descent. An ejection click and a prominent fourth sound $(A)$ are recorded at the fourth left intercostal space (4 LIS).

pattern (Table 3). The mean QRS axis in the frontal plane was shifted to the right in one patient $\left(+115^{\circ}\right)$ and was horizontal $\left(+180^{\circ}\right)$ in one other patient. In the 7 remaining cases it was superiorly oriented and situated between $-70^{\circ}$ and $-140^{\circ}$. No correlation was found between the QRS axis and the degree of pulmonary valve stenosis. The electrical axis of the $P$ wave was situated between $-20^{\circ}$ and $+60^{\circ}$. In 7 patients the right praecordial leads showed right ventricular hypertrophy with an $\mathrm{R}, \mathrm{Rs}$, or rsR' pattern. In 2 cases small rs or $\mathrm{rsr}^{\prime}$ complexes were seen in V3R and V1, despite right ventricular systolic pressures of $60 \mathrm{mmHg}$ and $190 \mathrm{mmHg}$. The QRS morphology in the left praecordial leads was also unusual. In 5 patients there was an $\mathrm{rS}$ pattern with a conspicuous $S$ wave in V5 and V6 (Fig. 4). Two of these had a small rs or rsr' $^{\prime}$ pattern in V3R, V1, and V2, so that no dominant $\mathbf{R}$ deflection was recorded in any of the praecordial leads. The electrocardiogram of the patient with the severest stenosis (case 10) is illustrative of this type of abnormality (Fig. 4). The 4 remaining children had a normal $\mathrm{qRs}$ or $\mathrm{qRS}$ pattern in V5 and V6.
The findings on the chest $x$-ray varied from normal to moderate right atrial and ventricular enlargement, in keeping with the degree of pulmonary stenosis. The only remarkable feature was the absence of prominent poststenotic dilatation in 6 of the 9 patients.

At cardiac catheterisation a systolic pressure gradient across the pulmonary valve was found in all children (Table 4). Right ventricular systolic pressure varied from 48 to $180 \mathrm{mmHg}$. Two patients (cases 10 and 16) had an additional infundibular gradient and 1 other patient (case 15) a small supravalvar gradient. An atrial left-to-right shunt was found in 3 patients, shown at operation to result from a small atrial septal defect of the fossa ovalis type in 2 patients and to a combination of atrial septal defect and partial anomalous pulmonary venous drainage of the right upper lobe in the other.

Right ventriculograms were obtained in 6 children. A dome-shaped valve with central jet of contrast material was observed in only 2 patients. In the 4 remaining cases very irregular and distorted valve cusps were seen in systole and an unusually 
q

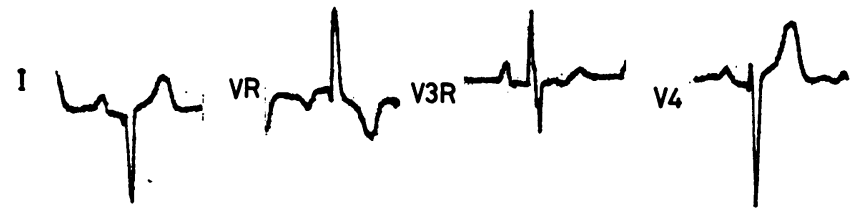

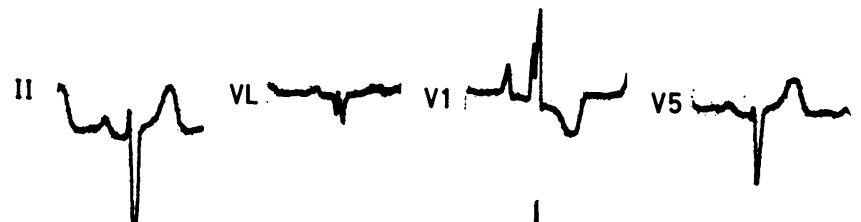

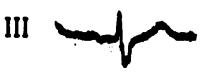<smiles>CCC1CCC1CF</smiles><smiles>[Y20]C(C)CCC</smiles>

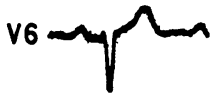

$\underline{b}$<smiles>CCC1CCC(CCI)C1CC</smiles><smiles>CCCCC(C)C=P</smiles>

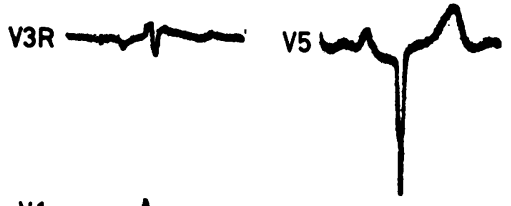

II<smiles>CCCC(C)CC</smiles><smiles>C1CC[Al]C1</smiles><smiles>CCCCC</smiles><smiles>CCCC(C)CC</smiles>
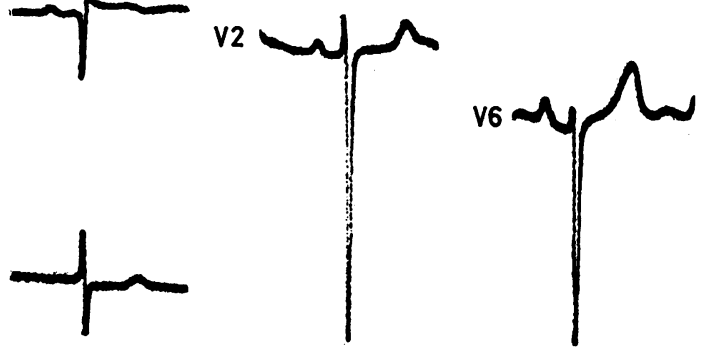

Fig. 4 (A) Electrocardiogram of case 17. Most conspicuous are the superiorly oriented $Q R S$ axis in the frontal plane and the deep $S$ wave in $V 5$ and $V 6$, in the presence of only mild pulmonary valve stenosis ( $R V$ pressure $70 \mathrm{mmHg}$ ). (B) Electrocardiogram of case 10. Note the rs pattern in V3R and V1 and deep $Q S$ and $r S$ complexes in V5 and $V 6$. The mean $Q R S$ axis in the frontal plane is horizontal $\left(+180^{\circ}\right)$.

thick 'filling defect' produced by the lumpy valve, in full diastole (Fig. 5). In 3 of these gross thickening or dysplasia of the pulmonary valve was found at operation. In 2 patients with severe valvar stenosis associated infundibular narrowing was shown. Some degree of poststenotic dilatation was present in all patients, even in those who showed no or minimal dilatation on the plain chest $x$-ray film. This discrepancy could be explained by slight rotation of the heart and a more median position of the right ventricular outflow tract.

All 8 patients with a pressure gradient in excess of $40 \mathrm{mmHg}$ underwent pulmonary valvotomy. In 4 the stenosis was found to be as usual, the valve 
Table 4 Haemodynamic data and surgical findings in 9 patients with Noonan's syndrome and pulmonary valve stenosis

\begin{tabular}{|c|c|c|c|c|c|c|}
\hline Case No. & $\begin{array}{l}R V \text { systolic } \\
\text { pressure } \\
(m m H g)\end{array}$ & $\begin{array}{l}\text { Infundibular } \\
\text { systolicpressure } \\
\text { (mmHg) }\end{array}$ & $\begin{array}{l}\text { PA systolic } \\
\text { pressure } \\
(\boldsymbol{m m H g})\end{array}$ & Associated defect & $\dot{Q}_{p} / \dot{Q}_{s}$ & $\begin{array}{l}\text { Anatomy of stenosed } \\
\text { pulmonary valve at surgery }\end{array}$ \\
\hline $\begin{array}{l}10 \\
11 \\
12 \\
13 \\
14 \\
15 \\
15 \\
16 \\
17 \\
18\end{array}$ & $\begin{array}{r}180 \\
150 \\
60 \\
48 \\
88 \\
80 \\
140 \\
100 \\
90\end{array}$ & $\begin{array}{l}= \\
= \\
= \\
= \\
- \\
-\end{array}$ & $\begin{array}{l}\frac{14}{18} \\
20 \\
22 \\
18^{*} \\
28 \\
18 \\
32\end{array}$ & $\begin{array}{l}\text { ASD } \\
\text { ASD, SVPS, PAPVR }\end{array}$ & $\begin{array}{l}1.5 \\
1.7 \\
1.2\end{array}$ & $\begin{array}{l}\text { classical } \\
\text { classical } \\
\text { dysplasia } \\
\text { not operated } \\
\text { classical } \\
\text { classical } \\
\text { dysplasia } \\
\text { dysplasia } \\
\text { no fusion of commissures } \\
\text { dysplasia }\end{array}$ \\
\hline
\end{tabular}

RV, right ventricle; PA, pulmonary artery; $\dot{\mathrm{Q}} / \dot{\mathrm{Q} s}$, pulmonary/systemic flow ratio; ASD, atrial septal defect; SVPS, supravalvar pulmonary stenosis; PAPVR, partial anomalous pulmonary venous return.

* Systolic pressure in main pulmonary trunk was $45 \mathrm{mmHg}$. Withdrawal tracing from pulmonary artery branches to main pulmonary trunk showed consistent gradient.
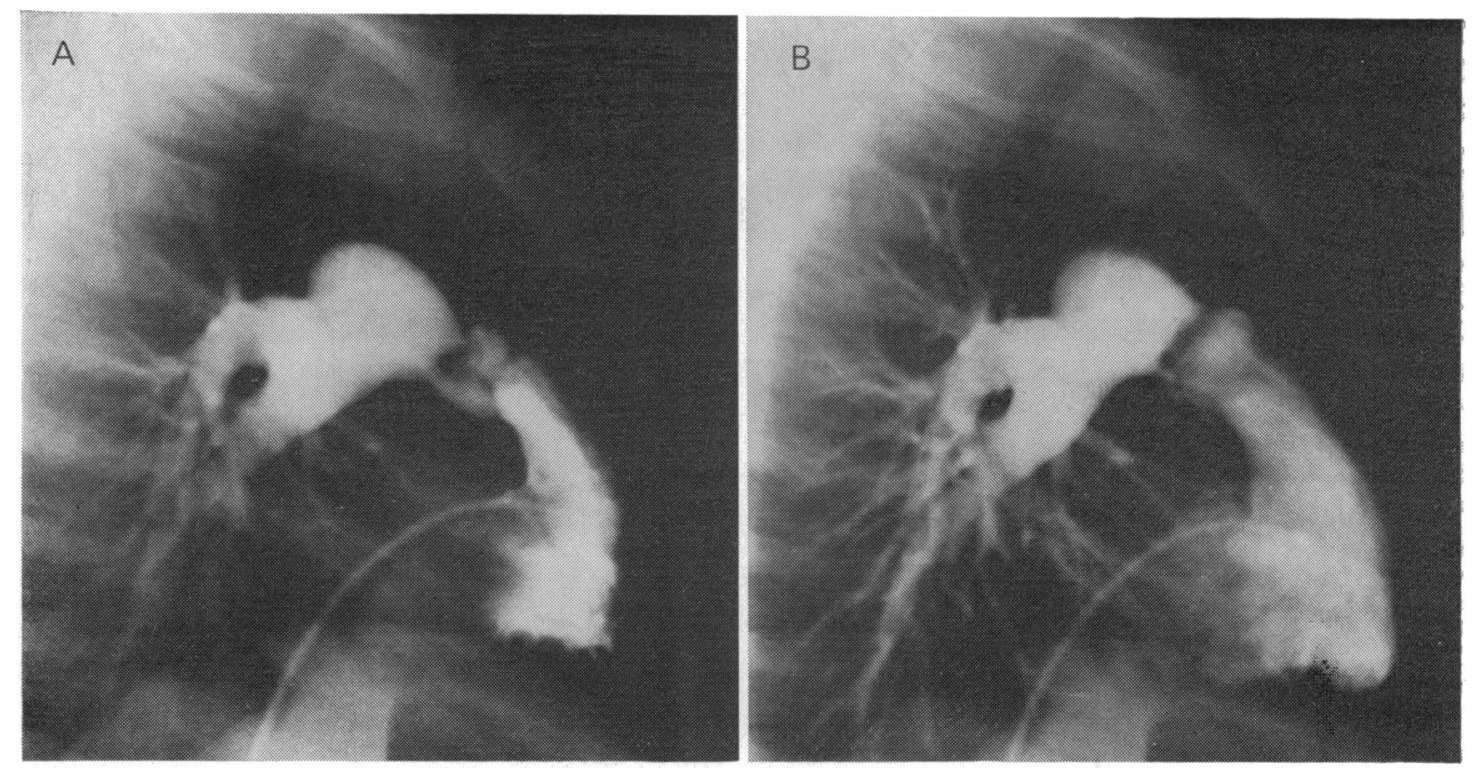

Fig. 5 Angiocardiograms from a 10-year-old boy (case 17) with Noonan's syndrome and severe dysplasia of the pulmonary valve. In systole $(A)$ the irregularity of the cusps and absence of dome formation is evident. The thickness of the cusps is best seen in diastole $(B)$.

being pliable, tricuspid, and with fused commissures. In 4 cases the valve was grossly thickened and stiff. In 3 of these this particular valve structure did not lead to surgical difficulties, and commissurotomy almost completely abolished the gradient. In the remaining patient (case 17), however, the obstruction seemed to be produced to a large extent by the lumpy and distorted leaflets, rather than by fusion of commissures. The gradient was only slightly reduced by commissurotomy. In this patient there was a considerable residual gradient at postoperative catheterisation: right ventricular and pulmonary arterial pressures were 68 and $22 \mathrm{mmHg}$, respectively, compared with 100 and $18 \mathrm{mmHg}$ before operation. The postoperative course was uneventful in all.

\section{Discussion}

Conclusions about the incidence of congenital heart disease in Turner's and Noonan's syndrome cannot be drawn from this study as all patients were primarily referred for cardiac evaluation. In surveys in which this type of selection was not present, the incidence was found to be 20 per cent (Haddad and Wilkins, 1959) and 21 per cent (Vernant et al., 1966) in Turner's syndrome and 
47 per cent (Siggers and Polani, 1972), 35 per cent (Nora et al., 1974), and 50 per cent (Nora et al., 1975) in Noonan's syndrome.

In Turner's syndrome left-sided cardiovascular lesions predominate. In our series 4 patients had coarctation of the aorta, 4 had valvar aortic stenosis, and 1 had combined coarctation and aortic stenosis. In 1 patient the right subclavian artery originated below the coarctation and ran an anomalous retrooesophageal course. In the other patients the anatomy did not differ from the classical findings. One patient died a week after operation as a result of acute necrotising arteritis involving the superior mesenteric artery. Though transient abdominal pain and, supposedly, localised arteritis have occasionally been reported after resection of coarctation, it should be noted that in our institution this girl with Turner's syndrome is the only patient in this age group who had died from this complication. It is possible that abnormal fragility of the arterial wall was the cause of this extensive necrosis. A few cases of cystic medial necrosis of large arteries, including the mesenteric arteries, have indeed been described in Turner's syndrome (Kostich and Opitz, 1965). In the present case, however, no such lesions were found in the limited segments of arteries that were histologically examined.

The prevalence of left-sided lesions is also evident from previous publications. In a series of 55 patients with Turner's phenotype, Haddad and Wilkins (1959) found 8 coarctations among the 11 patients with cardiovascular anomalies. An equally high incidence of coarctation was reported by Rainier-Pope et al. (1964) in girls with negative sex chromatin and by Nora et al. (1970) in patients with Turner's syndrome in whom the X0 karyotype was established. In the latter study out of 16 patients, 11 had coarctation, 2 ventricular septal defect, 1 atrial septal defect, 1 persistent ductus arteriosus, and 1 dextrocardia. $\mathrm{A}$ high incidence of aortic stenosis, as seen in our series, has only been mentioned by Vernant et al. (1966) who found it in 5 out of 6 patients. As observed by Nora et al. (1970) no patient has been reported with XO Turner's syndrome and pulmonary stenosis.

One girl with a mosaic $45, \mathrm{X} 0 / 46, \mathrm{XX}$ pattern had mild aortic valve stenosis. Two patients with this type of mosaicism described by Emerit et al. (1967) had coarctation, whereas 4 others reported by Nora et al. (1970) had pulmonary stenosis.

Although a wide variety of cardiac and vascular diseases are encountered in patients with Noonan's syndrome, the great majority presents with pulmonary valve stenosis (Celermajer et al., 1968; Dupuis et al., 1968; Noonan, 1968; Nora et al.,
1970). The prevalence of this anomaly in most cardiological studies may be the result of a certain bias which leads the cardiologist to make the diagnosis of Noonan's syndrome more readily when there is pulmonary stenosis than when any other cardiac malformation is present. This is borne out by the observation that the incidence of pulmonary stenosis is lower in surveys based on patients collected from various departments and not exclusively from the cardiac clinic (Char et al., 1972; Siggers and Polani, 1972) and in familial cases (Char et al., 1972; Ehlers et al., 1972).

In addition to pulmonary valve stenosis, which was present in all 9 children of this series, an atrial septal defect was found in 2 patients and an atrial septal defect associated with mild supravalvar pulmonary stenosis and anomalous drainage of the right upper pulmonary veins into the superior vena cava in 1 patient. In 2 previous studies atrial septal defect was found to be the second most frequent anomaly (Vernant et al., 1966; Char et al., 1972). In other reports small numbers of patients had persistent ductus arteriosus (Vernant et al., 1966; Noonan, 1968; Siggers and Polani, 1972), coarctation of the aorta (Vernant et al., 1966; Ehlers et al., 1972), and ventricular septal defect (Char et al., 1972; Nora et al., 1972). Single observations of Ebstein's anomaly (Wright et al., 1968) and systolic prolapse of the mitral valve (Towne et al., 1975) have been reported.

Left ventricular cardiomyopathy in Noonan's syndrome was first described by Ehlers et al. (1972) in familial cases. Severe left ventricular involvement, in some patients leading to congestive heart failure and death, has been reported by Phornphutkul et al. (1973) and by Hirsch et al. (1975). Early recognition of asymptomatic cases is now possible by means of echocardiography. A recent study indicates that asymmetrical septal hypertrophy is common in individuals with Noonan's syndrome not clinically suspected of having cardiac disease (Nora et al., 1975).

Very intriguing are the anatomical, clinical, and electrocardiographic features which distinguish pulmonary valve stenosis in patients with Noonan's syndrome from the usual findings in this cardiac anomaly. Gross thickening and dysplasia of the pulmonary valve were found in 4 of the 8 patients who came to operation. In only 1 of them, however, could the deformity be described as pure dysplasia without fusion of commissures. In this situation the thickened, lumpy cusps themselves are the major cause of obstruction (Koretzky et al., 1969; Linde et al., 1973) and, as observed in our patient, pulmonary valvotomy is bound to be unsatisfactory. From our observations and previous reports we 
may infer that this extreme degree of valve dysplasia is exceptional and that most patients have grossly thickened cusps associated with a varying degree of commissural fusion and dome formation. The angiocardiographic appearance of the valve is often characteristic. The filling defect produced by the thickened cusps, recognisable in systole and in diastole, is more conspicuous and irregular than in other patients with pulmonary stenosis.

Lack of valve mobility may account for the absence of an ejection sound in a number of patients. On the whole, however, the auscultatory and phonocardiographic observations in the present study did not differ significantly from the classical findings in pulmonary valve stenosis. The electrocardiogram, on the contrary, is often unusual. The mean frontal plane QRS axis was superiorly oriented and situated between $-70^{\circ}$ and $-140^{\circ}$ in 7 patients. In 1 child the axis was horizontal $\left(+180^{\circ}\right)$ and in the remaining patient $+115^{\circ}$. Evidence of right ventricular hypertrophy was lacking in the right praecordial leads in 2 patients with severe stenosis. In these and in 3 other patients an rS pattern was seen in the left praecordial leads. Noonan, in her original publication (1968), commented on the atypical mean QRS axis and the poor correlation between the height of the $R$ wave in V1 and the severity of the stenosis. In about half of the 18 patients in whom a vectocardiogram was recorded, Char et al. (1972) found a superiorly oriented counterclockwise QRS loop in the frontal plane. Left axis deviation, with or without $\mathrm{rS}$ waves in the left praecordial leads, is associated not only with pulmonary valve stenosis, but has also been found in patients with Noonan's syndrome and cardiomyopathy of the left ventricle (Ehlers et al., 1972; Phornphutkul et al., 1973; Hirsch et al., 1975). Koretzky et al. (1969) who were probably unaware of Noonan's publication, described left axis deviation as a constant feature in a group of patients with pulmonary valve dysplasia and facial stigmata in all respects characteristic of Noonan's syndrome.

As this unusual left axis deviation bears some resemblance to the electrocardiographic pattern of left anterior hemiblock seen in some patients with hypertrophic cardiomyopathy, it is tempting to attribute it to myocardial changes and altered conduction. In the few pathological reports on cases of Noonan's syndrome, widespread myocardial hypertrophy and fibrosis have either been the main findings and cause of death (Ehlers $e t$ al., 1972; Phornphutkul et al., 1973; Hirsch et al., 1975) or an incidental finding in patients with otherwise 'isolated' pulmonary valve stenosis (Beçu et al., 1976). The latter study, in which changes resembling hypertrophic cardiomyopathy were found, and recent echocardiographic investigation (Nora et al., 1975) suggest that generalised myocardial disease in Noonan's syndrome is more common than has hitherto been thought. However, detailed electrophysiological and histological studies of the conduction system will be needed to elucidate further the link between the electrocardiographic changes and this myocardial involvement.

All patients were operated on by Professor G. Stalpaert or Dr W. Daenen. We are grateful to them for informing us about the surgical findings and the postoperative course.

\section{References}

Beçu, L., Somerville, J., and Gallo, A. (1976). 'Isolated' pulmonary valve stenosis as part of more widespread cardiovascular disease. British Heart fournal, 38, 472-482.

Celermajer, J. M., Bowdler, J. D., and Cohen, D. H. (1968). Pulmonary stenosis in patients with the Turner phenotype in the male. American fournal of Diseases of Children, 116, 351-358.

Char, F., Rodriguez-Fernandez, H. L., Scott, C. I., Borgaonkar, D. S., Bell, B. B., and Rowe, R. D. (1972). The Noonan syndrome. A clinical study of forty-five cases. Birth Defects, 8, 110-118.

Dupuis, C., Nuyts, J-P., Maillard, E., Bouvier, C., Lefebvre, P., Fontaine, G., and Gaudier, B. (1968). Le syndrome dit de 'Turner male'. Archives Françaises de Pédiatrie, 25, 511-530.

Ehlers, K. H., Engle, M. A., Levin, A. R., and Deely, W. J. (1972). Eccentric ventricular hypertrophy in familial and sporadic instances of $46 \mathrm{XX}, \mathrm{XY}$ Turner phenotype. Circulation, 45, 639-652.

Emerit, I., De Grouchy, J., Vernant, P., and Corone, P. (1967). Chromosomal abnormalities and congenital heart disease. Circulation, 36, 886-905.

Ford, C. E., Jones, K. W., Polani, P. E., de Almeida, J. C., and Briggs, J. H. (1959). A sex-chromosome anomaly in a case of gonadal dysgenesis (Turner's syndrome). Lancet, 1, 711-713.

Haddad, H. M., and Wilkins, L. (1959). Congenital anomalies associated with gonadal aplasia: review of 55 cases. Pediatrics, 23, 885-902.

Hirsch, H. D., Gelband, H., Garcia, O., Gottlieb, S., and Tamer, D. M. (1975). Rapidly progressive obstructive cardiomyopathy in infants with Noonan's syndrome. Circulation, 52, 1161-1165.

Koretzky, E. D., Moller, J. H., Korns, M. E., Schwartz, C. J., and Edwards, J. E. (1969). Congenital pulmonary stenosis resulting from dysplasia of valve. Circulation, 40, 43-53.

Kostich, N. D., and Opitz, J. M. (1965). Ullrich-Turner syndrome associated with cystic medial necrosis of the aorta and great vessels. American fournal of Medicine, 38, 943-950.

Lemli, L., and Smith, D. W. (1963). The X0 syndrome: a study of the differentiated phenotype in 25 patients. Fournal of Pediatrics, 63, 577-588.

Linde, L. M., Turner, S. W., and Sparkes, R. S. (1973). Pulmonary valvular dysplasia: a cardiofacial syndrome. British Heart fournal, 35, 301-304.

Noonan, J. A. (1968). Hypertelorism with Turner phenotype: a new syndrome with associated congenital heart disease. American fournal of Diseases of Children, 116, 373-380.

Noonan, J. A., and Ehmke, D. A. (1963). Associated non- 
cardiac malformations in children with congenital heart disease (abstract). Fournal of Pediatrics, 63, 468-470.

Nora, J. J., Lortscher, R. H., and Spangler, R. D. (1975). Echocardiographic studies of left ventricular disease in Ullrich-Noonan syndrome. American fournal of Diseases of Children, 129, 1417-1420.

Nora, J. J., Nora, A. H., Sinha, A. K., Spangler, R. D., and Lubs, H. A. (1974). The Ullrich-Noonan syndrome (Turner phenotype). American fournal of Diseases of Children, 127, 48-55.

Nora, J. J., and Sinha, A. K. (1967). Hereditary Turner phenotypes. Lancet, 2, 256-257.

Nora, J. J., Sinha, A. K., and Nora, A. H. (1972). Dominant inheritance of the Noonan syndrome. Birth Defects, 8, 119-121.

Nora, J. J., Torres, F. G., Sinha, A. K., and McNamara, D. G. (1970). Characteristic cardiovascular anomalies of XO Turner syndrome, $\mathrm{XX}$ and $\mathrm{XY}$ phenotype, and $\mathrm{X} 0 / \mathrm{XX}$ Turner mosaic. American fournal of Cardiology, 25, 639-641.

Phornphutkul, C., Rosenthal, A., and Nadas, A. S. (1973). Cardiomyopathy in Noonan's syndrome: report of three cases. British Heart fournal, 35, 99-102.

Polani, P. E., Lessof, M. H., and Bishop, P. M. (1956). Colour-blindness in 'ovarian agenesis' (gonadal dysplasia). Lancet, 2, 118-121.

Rainier-Pope, C. R., Cunningham, R. D., Nadas, A. S., and Crigler, J. F., Jr. (1964). Cardiovascular malformations in Turner's syndrome. Pediatrics, 33, 919-925.

Siggers, D. C., and Polani, P. E. (1972). Congenital heart disease in male and female subjects with somatic features of Turner's syndrome and normal sex chromosomes (Ullrich's and related syndromes). British Heart fournal, 34, 41-46.

Towne, W. D., Fabian, J. S., Rosen, K. M., and Rahimtoola, S. H. (1975). Systolic prolapse of the mitral valve in Noonan's syndrome. American Heart fournal, 90, 499-502.

Turner, H. H. (1938). A syndrome of infantilism, congenital webbed neck and cubitus valgus. Endocrinology, 23, 566-574.

Ullrich, O. (1930). Ueber typische Kombinationsbilder multipler Abartungen. Zeitschrift für Kinderheilkunde, 49, 271-276.

Van den Berghe, H. (1966). Het zogenaamde Syndroom van Turner. Thesis Leuven. Standaard Wetenschappelijke Uitgeverij, Antwerpen.

Vernant, P., Corone, P., Grouchy, J., Gennes, J. L., and Emerit, I. (1966). Le cœur dans le syndrome de TurnerUllrich. Archives des Maladies du Cour et des Vaisseaux, 59, 850-875.

Wright, N. L., Summitt, R. L., and Ainger, L. E. (1968). Noonan's syndrome and Ebstein's malformation of the tricuspid valve. American fournal of Diseases of Children, 116, 367-372.

Requests for reprints to $\mathrm{Dr}$ L. G. Van der Hauwaert, Section of Paediatric Cardiology, University Hospital Gasthuisberg, 3000 Leuven, Belgium. 